\title{
Epidemiological Risk Factors and Perinatal Outcomes of Congenital Anomalies
}

\section{Fatores de risco epidemiológicos e resultados perinatais das anomalias congênitas}

\author{
Lissa Fernandes Garcia Almeida ${ }^{1}$ Edward Araujo Júnior ${ }^{2}$ Gerson Claudio Crott ${ }^{1}$ \\ Marcos Masaru Okido ${ }^{1}$ Aderson Tadeu Berezowski ${ }^{1}$ Geraldo Duarte ${ }^{1}$ Alessandra Cristina Marcolin ${ }^{1}$ \\ ${ }^{1}$ Department of Gynecology and Obstetrics, Faculdade de Medicina \\ de Ribeirão Preto, Universidade de São Paulo, Ribeirão Preto, \\ São Paulo, Brazil \\ 2 Department of Obstetrics, Universidade Federal de São Paulo, São \\ Paulo, São Paulo, Brazil \\ Rev Bras Ginecol Obstet 2016;38:348-355. \\ Address for correspondence Edward Araujo Júnior, PhD, Rua \\ Napoleão de Barros, 875, Vila Clementino, 04024-002, São Paulo, SP, \\ Brazil (e-mail: araujojred@terra.com.br).
}

received

February 25, 2016

accepted

June 10, 2016

published online

July 23, 2016
Objectives To identify the epidemiological risk factors for congenital anomalies (CAs) and the impact of these fetal malformations on the perinatal outcomes.

Methods This prospective cohort study comprised 275 women whose fetuses had CAs. Maternal variables to establish potential risk factors for each group of CA and perinatal outcomes were evaluated. The primary outcome was CA. Secondary outcomes included: fetal growth restriction (FGR); fetal distress (FD); premature rupture of membranes (PROM); oligohydramnios or polyhydramnios; preterm delivery (PTD); stillbirth; cesarean section; low birth weight; Apgar score $<7$ at the 1st and 5th minutes; need for assisted ventilation at birth; neonatal infection; need for surgical treatment; early neonatal death; and hospitalization time. Chi-square $\left(\chi^{2}\right)$ test and multilevel regression analysis were applied to compare the groups and determine the effects of maternal characteristics on the incidence of CAs.

Results The general prevalence of CAs was of $2.4 \%$. Several maternal characteristics were associated to CAs, such as: age; skin color; level of education; parity; folic acid supplementation; tobacco use; and history of previous miscarriage. There were no significant differences among the CA groups in relation to FGR, FD, PROM, 1-minute Apgar score $>7$, and need for assisted ventilation at birth. On the other hand, the prevalence of the other considered outcomes varied significantly among groups. Preterm delivery was significantly more frequent in gastrointestinal tract/abdominal wall defects. The stillbirth rate was increased in all CAs, mainly in isolated fetal hydrops (odds ratio [OR]: 27.13; 95\% confidence interval [95\%Cl]: 2.90-253.47). Hospitalization time was higher for the urinary tract and congenital heart disease groups $(p<0.01)$. Neonatal death was significantly less frequent in the central nervous system anomalies group.

- ultrasound

- perinatal outcome

DOI http://dx.doi.org/ $10.1055 / \mathrm{s}-0036-1586160$. ISSN $0100-7203$.
Copyright $(2016$ by Thieme Publicações License terms

Ltda, Rio de Janeiro, Brazil
(1) $\Theta \circledast$ 


\section{Resumo}

\author{
Palavras-chave \\ - gestação \\ - anomalias congênitas \\ - fatores \\ epidemiológicos de \\ risco \\ - ultrassom \\ - resultado perinatal
}

Conclusion It was possible to identify several risk factors for CAs. Adverse perinatal outcomes were presented in all CA groups, and may differ according to the type of CA considered.

Objetivos Identificar os fatores epidemiológicos de risco para anomalias congênitas (ACs) e o impacto destas malformações fetais sobre os resultados perinatais.

Métodos Este estudo de coorte prospectivo compreendeu 275 mulheres cujos fetos tinham ACs. Variáveis maternas para estabelecer potenciais fatores de risco para cada grupo de AC e resultados perinatais foram avaliados. O desfecho primário foi CAs. Os desfechos secundários incluíram: restrição de crescimento fetal (RCF); sofrimento fetal (SF); ruptura prematura de membranas (RPM); oligo-hidrâmnio ou polidrâmnio; parto pré-termo (PPT); morte fetal; parto cesárea; baixo peso ao nascer; índice de Apgar $<7$ no $1^{\circ}$ e $5^{\circ}$ minutos; necessidade de ventilação assistida no momento do nascimento; infecção neonatal; necessidade de tratamento cirúrgico; óbito neonatal precoce; e tempo de internação. Teste de Qui-quadrado $\left(\chi^{2}\right)$ e análise de regressão múltipla foram aplicados para comparar os resultados entre os grupos e determinar os efeitos das características maternas sobre a incidência de ACs.

Resultados A prevalência geral de ACs foi de $2.4 \%$. Várias características maternas foram associadas às ACs, tais como: idade; cor da pele; escolaridade; paridade; suplementação com ácido fólico; tabagismo; e histórico de aborto anterior. Não houve diferenças significativas entre os grupos de ACs com relação à RCF, SF, RPM, índice de Apgar $<7$ no $1^{\circ}$ minuto e necessidade de ventilação assistida no nascimento. Por outro lado, a prevalência dos demais resultados adversos considerados variou significativamente entre os grupos. O parto pré-termo foi significativamente mais frequente nos casos de defeitos do trato gastrointestinal/parede abdominal. As taxas de óbito fetal foram elevadas em todos os grupos de ACs, principalmente na hidropsia fetal isolada (odds ratio [OR]: 27.13; intervalo de confiança de 95\% [IC95\%]: 2.90-253.47). O tempo de internação foi maior nos casos de anomalias do trato urinário e nas cardiopatias congênitas $(p<0,01)$. O óbito neonatal foi significativamente menos frequente no grupo de anomalias do sistema nervoso central.

Conclusão Foi possível identificar vários fatores de risco para ACs. Resultados perinatais adversos foram observados em todos os grupos de ACs, e podem diferir de acordo com o tipo de AC considerada.

\section{Introduction}

Congenital anomalies (CAs), fetal growth restriction and prematurity are the main causes of morbidity and mortality during childhood. ${ }^{1,2}$ The etiologies of many developmental disorders are poorly understood; however, some risk factors have already been identified, such as environmental or occupational exposures, ${ }^{3}$ medications, ${ }^{4}$ smoking, ${ }^{5}$ the use of illicit drugs ${ }^{6}$ and alcohol $^{7}$; maternal diseases, such as pregestational diabetes mellitus ${ }^{8}$ and thyroid dysfunction; ${ }^{9}$ and congenital infections. ${ }^{10,11}$

The European Surveillance of Congenital Anomalies (EUROCAT) recorded a total prevalence of major CAs of 23.9 per 1,000 births for $2003-2007 .{ }^{12}$ According to this network, $80 \%$ of those were livebirths, $2.0 \%$ were stillbirths or fetal deaths from 20 weeks gestation, and $17.6 \%$ of all cases were terminations of pregnancy. Among the live births with CAs, 2.5\% died during the first week of life. Congenital heart defects were the most common CA in euploid fetuses, followed by limb defects, urinary tract malformations and central nervous system anomalies. A better understanding of the possible risk factors associated with CAs is crucial for the primary prevention, especially during the preconceptional period. ${ }^{13}$ Furthermore, prenatal diagnosis of CAs is important for adequate perinatal management in a tertiary healthcare service with a multidisciplinary team to decrease morbidity and mortality rates, ${ }^{14-16}$ mainly in countries where the termination of pregnancy is not allowed. ${ }^{17}$

The prenatal ultrasound accuracy to detect CAs ranges in different countries (31-61\%), which seems to be related to the health public policy regarding the prenatal ultrasound screening programs. ${ }^{18-20}$ Since CAs are highly prevalent and associated with adverse perinatal outcomes, an adequate prenatal diagnosis is imperative for an appropriate perinatal management, allowing the reduction of perinatal morbidity and mortality rates. Therefore, surveillance networks of CAs able to point out weak points in prenatal screening policies 
could contribute for implementing the required improvements and increase the detection rates of fetal malformations.

Despite the fact that CAs are a highly reported topic in scientific literature, very little information is available regarding the potential risk factors associated with these anomalies and their perinatal outcomes. Thus, the objectives of the present study were to identify the epidemiological risk factors for CAs and evaluate the impact of these fetal defects on the perinatal outcome.

\section{Methods}

This prospective cohort study comprised 289 high-risk pregnant women whose fetuses had CAs. All participants were recruited from the group of women admitted to the university hospital of the Faculdade de Medicina de Ribeirão Preto, São Paulo, Brazil, from September 2011 to July 2013. This 34-bed unit is a Fetal Medicine reference center in Brazil covering an area of 2 million inhabitants in the north of the State of São Paulo. This tertiary healthcare service serves $\sim 1,800$ high-risk pregnant women per year within the Brazilian public health system. The aim and methodology of the study was explained to all recruited women. Voluntary participation was requested, and informed consent was obtained. This study was approved by the local Ethics Research Committee (protocol number 6319/ 2011) in agreement with the current procedures and according to the internationally acknowledged Strengthening the Reporting of Observational Studies in Epidemiology (STROBE) criteria. The inclusion criteria were: 1) pregnant women carrying fetuses with CAs diagnosed at any trimester of pregnancy; and 2) gestational age determined by the last menstrual period and confirmed by ultrasound exam performed until 13th week. Following the exclusion of subjects throughout the study, data from 275 pregnant women were used for the current analysis. Fourteen subjects were excluded by the following reasons: failure to follow-up $(n=9)$ and inability to obtain all data from medical records $(n=5)$.

All recruited pregnant women were referred to our service from primary or secondary public healthcare services after an ultrasound level I demonstrating CAs. After admission to the institution, the pregnant women were submitted to an ultrasound level III to properly diagnose the CA. All scans were transabdominal, using a 4-8 $\mathrm{MHz}$ probe (Voluson 730 Expert, GE Medical Systems, Milwaukee, WI, USA) operated by experienced sonographers who had the appropriate Fetal Medicine Certificate of Competence in the fetal anomaly assessment. During the prenatal follow-up, the pregnant women had genetic counselling, psychological support, and additional appointments with a multidisciplinary team (neonatologists, pediatric surgeons, neurosurgeons, cardiovascular surgeons, and anesthesiologists). Termination of pregnancy was not performed, since it is not allowed by the country's laws (except in the case of anencephaly). Maternal demographic characteristics and ultrasonographic findings were recorded in a computer database. Details regarding pregnancy and neonatal outcomes were added to the database as soon as they became available.

\section{Definitions and Outcomes}

For data analysis, CAs were divided into seven groups according to type: 1) central nervous system (CNS); 2) urinary tract (UT); 3) heart and great vessels (HGV); 4) gastrointestinal tract/abdominal wall (GI); 5) musculoskeletal (ME); (6) isolated fetal hydrops; and 7) others. This latter category comprised fetuses with multiple malformations, congenital diaphragmatic hernia, and tumors.

The primary outcome was CA. The following maternal variables were considered as potential risk factors for each group of CA: age ( $<19$ years, $20-35$ and $>35$ years); skin color (white or non-white); level of education ( $\leq 8$ years, $>8$ years); professional activity (with or without); body mass index (normal, overweight or obese); smoking; use of medications with teratogenic potential; regular folic acid supplementation; parity (primigravida, secundigravida, multigravida); history of previous miscarriage; and chronic diseases.

Secondary outcomes included: fetal growth restriction (estimated fetal weight $<10$ th percentile for the gestational age) ${ }^{21}$ fetal distress followed by cesarean section; premature rupture of membranes; oligohydramnios or polyhydramnios (single deepest pocket $<5$ th percentile or $>95$ th for the gestational age); ${ }^{22}$ preterm delivery (birth before 37 weeks of gestation); stillbirth (fetal death after 20 weeks of gestation); cesarean section; low birth weight (below 2,500 g); Apgar score $<7$ at the 1 st and 5th minutes; need for assisted ventilation at birth; neonatal infection; need for surgical treatment; and early neonatal death.

\section{Statistical Analysis}

A sample size of 250 fetuses (subjects) was estimated based on the prevalence of CAs of $1.5 \%$ in the general population, and the detection rate of $3.0 \%$ in the high-risk population, considering a significance level of $5 \%$ and power of $80 \%$. However, considering a $10 \%$ of failure to follow-up, a sample size of 275 would be enough to perform this study.

Mean, standard deviation (SD), median, minimum and maximum were used to describe the variable hospitalization time. Percentages were used to describe qualitative variables. The Chi-square $\left(\chi^{2}\right)$ test was applied to verify the association between the categorical variables and CAs. Simple and multiple logistic regression analyses were used to determine the effects of maternal characteristics on the incidence of CAs at birth and the influence of types of CA on the perinatal outcomes. ${ }^{23}$ The Kruskal-Wallis or Mann-Whitney tests were applied to verify the differences in secondary outcomes among CAgroups. All analyses were performed using the SAS software version 9.0 (Cary, North Carolina, USA). A $p<0.05$ was considered statistically significant.

\section{Results}

The general prevalence of CAs was of $2.4 \%$. The following groups of birth defects were identified: CNS ( $n=78,28.4 \%)$; $\mathrm{UT}(n=59,21.5 \%) ; \operatorname{HGV}(n=32,11.6 \%) ; \mathrm{GI}(n=38,13.8 \%)$; ME $(n=18,6.6 \%)$; hydrops $(n=15,54 \%)$; and others 
( $n=35,12.7 \%)$ - - Table 1 shows the maternal demographic variables taking into account different CA groups. We observed a higher rate of pregnant women with higher levels of education ( $>8$ years) in the HGV defects and hydrops groups $(p=0.041)$. Other maternal variables did not differ significantly among the CA groups; however, some findings should be highlighted. There were more teenagers in the GI and ME groups. The proportions of women who used medications were higher in the CNS and UT groups. Furthermore, we noticed higher rates of pregnant women smokers in the GI and ME groups. In addition, folic acid supplementation was less common in the GI group; there was a higher rate of multigravida in the HGV group, and a higher rate of women with previous miscarriages in the hydrops group.

- Table 2 shows the concordance between the ultrasound levels I III performed by a Maternal-Fetal Medicine specialist.

Table 1 Maternal demographic variables taking into account different groups of congenital anomalies

\begin{tabular}{|c|c|c|c|c|c|c|c|c|}
\hline & \multicolumn{7}{|c|}{ Type of congenital anomaly } & \multirow[t]{2}{*}{$p$} \\
\hline & $\begin{array}{l}\text { Central } \\
\text { nervous } \\
\text { system (\%) }\end{array}$ & $\begin{array}{l}\text { Urinary } \\
\text { tract (\%) }\end{array}$ & $\begin{array}{l}\text { Heart and } \\
\text { great } \\
\text { vessels (\%) }\end{array}$ & $\begin{array}{l}\text { Gastrointestinal/ } \\
\text { abdominal } \\
\text { wall (\%) }\end{array}$ & $\begin{array}{l}\text { Musculoskeletal } \\
(\%)\end{array}$ & $\begin{array}{l}\text { Isolated } \\
\text { hydrops } \\
\text { (\%) }\end{array}$ & $\begin{array}{l}\text { Others } \\
\text { (\%) }\end{array}$ & \\
\hline $\begin{array}{l}\text { Maternal age } \\
(\text { mean } \pm S D)\end{array}$ & $25.55 \pm 6.0$ & $26.24 \pm 6.6$ & $27.23 \pm 7.0$ & $23.32 \pm 7.8$ & $24.50 \pm 5.8$ & $28.47 \pm 5.1$ & $28.07 \pm 7.4$ & \\
\hline$\leq 19$ years & 14.1 & 18.6 & 12.5 & 28.9 & 27.8 & 0.0 & 8.6 & \multirow[t]{3}{*}{ NS } \\
\hline $20-35$ years & 78.2 & 69.5 & 68.7 & 63.2 & 66.7 & 93.3 & 71.4 & \\
\hline$>35$ years & 7.7 & 11.9 & 18.8 & 7.9 & 5.5 & 6.7 & 20.0 & \\
\hline \multicolumn{9}{|l|}{ Skin color } \\
\hline White & 88.5 & 79.7 & 75.0 & 76.3 & 72.2 & 86.7 & 77.1 & \multirow[t]{2}{*}{ NS } \\
\hline Non-white & 11.5 & 20.3 & 25.0 & 23.7 & 27.8 & 13.3 & 22.9 & \\
\hline \multicolumn{9}{|c|}{ Level of education } \\
\hline$\leq 8$ years & 44.9 & 61.0 & 34.4 & 60.5 & 55.6 & 26.7 & 40.0 & \multirow[t]{2}{*}{0.041} \\
\hline$>8$ years & 55.1 & 39.0 & 65.6 & 39.5 & 44.4 & 73.3 & 60.0 & \\
\hline \multicolumn{9}{|l|}{ Occupation } \\
\hline Without & 53.8 & 67.8 & 43.7 & 65.8 & 72.2 & 40.0 & 51.4 & \multirow[t]{2}{*}{ NS } \\
\hline With & 46.2 & 32.2 & 56.3 & 34.2 & 27.8 & 60.0 & 48.6 & \\
\hline \multicolumn{9}{|l|}{ Chronic diseases } \\
\hline Yes & 15.4 & 20.3 & 12.5 & 13.2 & 22.2 & 0.0 & 25.7 & \multirow[t]{2}{*}{ NS } \\
\hline No & 84.6 & 79.7 & 87.5 & 86.8 & 77.8 & 100.0 & 74.3 & \\
\hline \multicolumn{9}{|l|}{ Smoking } \\
\hline Yes & 11.5 & 6.8 & 9.4 & 18.4 & 27.8 & 20.0 & 2.8 & \multirow[t]{2}{*}{ NS } \\
\hline No & 88.5 & 93.2 & 90.6 & 81.6 & 72.2 & 80.0 & 97.2 & \\
\hline \multicolumn{9}{|c|}{ Body mass index $\left(\mathrm{kg} / \mathrm{m}^{2}\right)$} \\
\hline Normal & 56.4 & 54.3 & 62.5 & 52.6 & 44.4 & 40.0 & 42.9 & \multirow[t]{3}{*}{ NS } \\
\hline Overweight & 24.3 & 28.8 & 28.1 & 34.2 & 44.4 & 40.0 & 40.0 & \\
\hline Obese & 19.3 & 16.9 & 9.4 & 13.2 & 11.2 & 20.0 & 17.1 & \\
\hline \multicolumn{9}{|l|}{ Medication use } \\
\hline Yes & 14.1 & 8.5 & 9.4 & 10.5 & 5.6 & 6.7 & 14.3 & \multirow[t]{2}{*}{ NS } \\
\hline No & 85.9 & 91.5 & 90.6 & 89.5 & 94.4 & 93.3 & 85.7 & \\
\hline \multicolumn{9}{|c|}{ Folic acid supplementation } \\
\hline Yes & 32.1 & 25.4 & 37.5 & 13.2 & 38.9 & 20.0 & 31.4 & \multirow[t]{2}{*}{ NS } \\
\hline No & 67.9 & 74.6 & 62.5 & 86.8 & 61.1 & 80.0 & 68.6 & \\
\hline \multicolumn{9}{|l|}{ Parity } \\
\hline Primigravida & 46.2 & 35.6 & 31.2 & 42.1 & 38.9 & 33.3 & 37.1 & \multirow[t]{3}{*}{ NS } \\
\hline Secundigravida & 28.2 & 28.8 & 21.9 & 23.7 & 22.2 & 46.7 & 31.4 & \\
\hline Multigravida & 25.6 & 35.6 & 48.9 & 34.2 & 38.9 & 20.0 & 31.5 & \\
\hline \multicolumn{9}{|c|}{ Previous miscarriage } \\
\hline Yes & 14.1 & 20.3 & 21.9 & 26.3 & 22.2 & 33.3 & 22.9 & \multirow[t]{2}{*}{ NS } \\
\hline No & 85.9 & 79.7 & 78.1 & 73.7 & 77.8 & 66.7 & 77.1 & \\
\hline
\end{tabular}

Abbreviation: NS, non-significant; SD, standard deviation. 
Table 2 Concordance between the ultrasound scan performed by non-specialists (level I) and Maternal-Fetal Medicine specialists (level III)

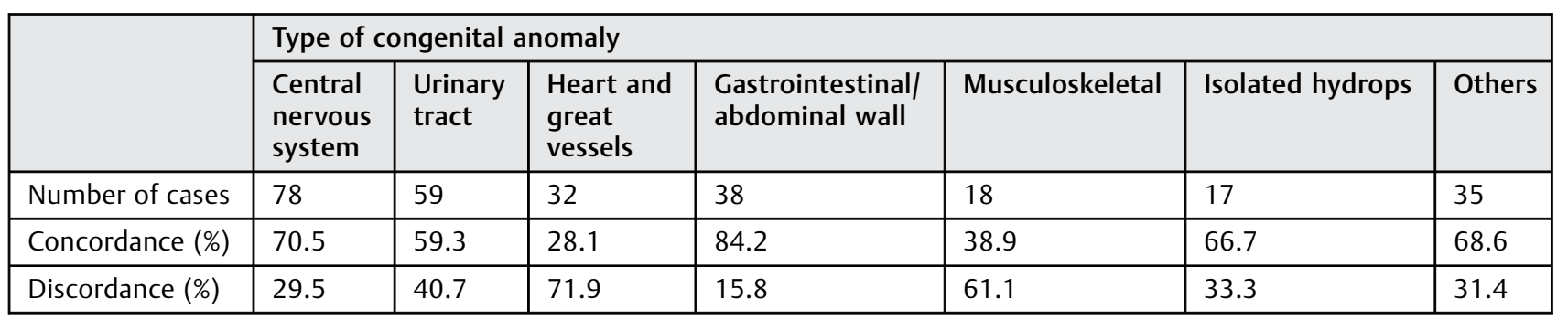

The highest concordance occurred in the GI defect group (84.2\%), and the lowest concordance was detected in the HGV defect group (28.1\%).

Multiple logistic regression analyses were applied to determine the effects of maternal parameters on the prevalence of a specific type of CA. Non-white skin color decreased the risk of CNS anomalies by nearly 60\% (OR: 0.43 ; 95\%CI: 0.19-0.97; $p=0.04)$. High levels of education decreased the risk of UT defects by almost 50\% (OR: 0.52; 95\%CI: 0.29-0.94; $p=0.03$ ). Primigravida showed a reduced risk of having a newborn with HGV defects (OR: 0.26; 95\%Cl: 0.08-0.80; $p=0.02$ ). In addition, maternal age $>19$ years and regular folic acid supplementation were associated with decreased risk of GI malformations by nearly $60 \%$ (OR: 0.42 ; 95\%CI: $0.19-0.95 ; p=0.04$ ) and 65\% (OR: $0.34 ; 95 \% \mathrm{CI}: 0.13-0.91 ; p=0.03$ ) respectively. Smoking increased the risk of ME anomalies by 3 times (OR: 3.28; 95\%CI: $1.08-9.90 ; p=0.04)$. Furthermore, history of previous miscarriage increased the risk of hydrops by almost 8 times (OR: 7.65; 95\%CI: $1.40-41.66 ; p=0.02$ ).
- Table 3 shows the perinatal outcomes considering different CA groups. The following perinatal complications were associated with CAs: polyhydramnios; oligohydramnios; stillbirth; preterm delivery; cesarean section; low birth weight; need for pressure support; neonatal infection; need for surgical treatment; and early neonatal death. Polyhydramnios was more common in the ME and hydrops groups specifically, with a prevalence of $38.9 \%$ (OR: 4.46 ; 95\%CI: $1.09-18.29$ ) and $40 \%$ (OR: 4.67; 95\%CI: 1.07-20.32) respectively. On the other hand, oligohydramnios was more common in the UT malformation group (OR: 12.55 ; 95\%CI: 1.58-99.38). The prevalence of stillbirth was high in all CA groups, mainly in the hydrops (OR: 27.13; 95\%CI: 2.90-253.47). Preterm delivery was very common in all CA groups (18.7-86.7\%), especially in the GI defects (OR: 5.96; 95\%CI: 1.99-17.84) and hydrops groups (OR: 28.16; 95\%CI: 4.98-159.38). The prevalence of low birth weight was high in all CA groups, mainly in the GI defects group (OR: 2.08; 95\%CI: 1.08-27.83), the ME anomalies group (OR: $3.34 ; 95 \% \mathrm{CI}: 1.34-38.52$ ) and in the others group (OR:

Table 3 Perinatal outcomes considering different groups of congenital anomalies

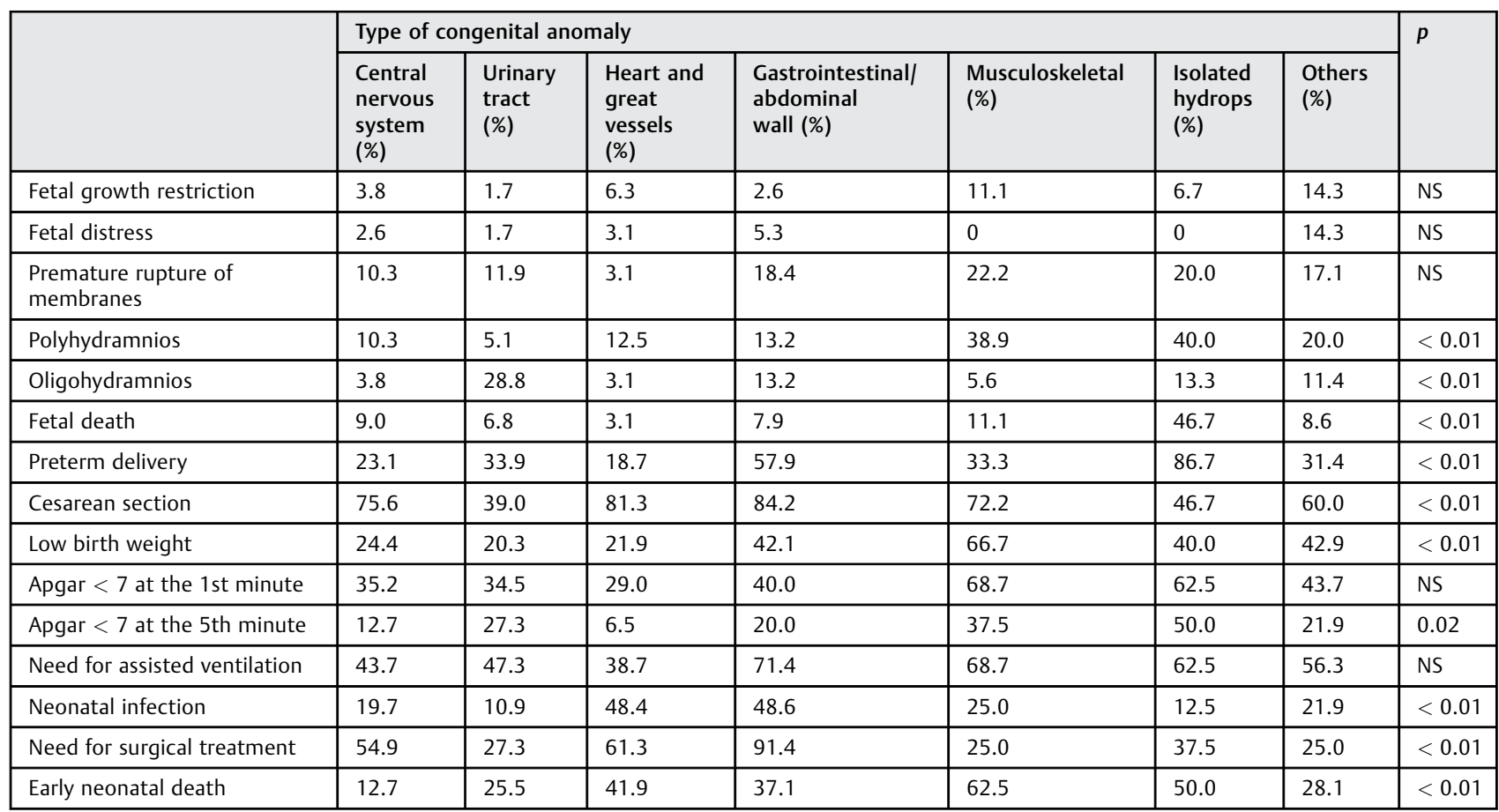

Abbreviation: NS, non-significant. 
1.98; 95\%CI: 1.05-7.25). Additionally, Apgar score $<7$ at the 5 th minute was high in all types of CA, especially in the UT malformations group (OR: 5.44; 95\%CI: 1.15-25.64), the ME anomalies group (OR: 8.70; 95\%CI: 1.51-50.28) and the hydrops group (OR: 14.50; 95\%CI: 1.98-106.44). Infections were less prevalent in the CNS defects group (OR: $0.26 ; 95 \% \mathrm{CI}$ : $0.11-0.65$ ), as well as in the UT anomalies group (OR: 0.13 ; 95\%CI: $0.04-0.39$ ) and in the others group (OR: $0.30 ; 95 \% \mathrm{CI}$ : $0.10-0.89)$. Surgeries were less necessary in the UT anomalies group (OR: 0.24; 95\%CI: 0.09-0.60), in the ME group (OR: 0.21; 95\%CI: $0.06-0.81$ ), and in the others group (OR: $0.21 ; 95 \% \mathrm{CI}$ : $0.07-0.62$ ). In contrast, it was more common in the GI group (OR: 6.74; 95\%CI: 1.68-26.96). Early neonatal death rate was high in all CA groups; however, it was significantly less common in the CNS defects group (OR: $0.20 ; 95 \% \mathrm{CI}$ : 0.07-0.55).

- Table 4 shows the hospitalization time of all CA groups. In general, the hospitalization time was higher in the subgroups of GI anomalies and HGV defects $(p<0.01)$. Hospitalization time was also higher in the subgroups in which surgery was required or had neonatal infection. On the other hand, hospitalization time was lower in the subgroups with Apgar scores $<7$ at the 5 th minute, probably because of their high mortality rate.

\section{Discussion}

In the present study, the prevalence of CAs was of $2.4 \%$, considering $\sim 10$ thousand ultrasound scans performed at our institution between 2011 and 2013. This rate is similar to the one from Dolk et al, ${ }^{12}$ who described the prevalence of CAs in Europe. Central nervous system anomalies, including open neural tube defects, were the most common CA detected in fetuses, a finding similar to those reported on other studies. The majority of the CAs of the fetal CNS is identified by the second-trimester ultrasound at 20-24 weeks of gestation, which makes them the most common. ${ }^{24}$ Furthermore, CNS defect was a CA group with high concordance (71\%) between ultrasound scans performed by non-specialists (level I) and Maternal-Fetal Medicine specialists (level III).

Urinary tract malformation constitutes $\sim 20 \%$ of all CAs, which is coincident with the data presented here. ${ }^{18}$ However, the concordance between the diagnoses made by sonographers with different levels of experience is lower than CNS anomalies. A possible explanation for this result would be that up to $80 \%$ of UT malformations can be solved spontaneously during fetal life, or worsened with advancing gestational age and impaired fetal renal function. ${ }^{25}$ Multicystic dysplasia might not be identified in the second trimester

Table 4 Hospitalization time of live newborns according to the congenital anomaly group and their perinatal outcomes

\begin{tabular}{|c|c|c|c|c|c|c|c|}
\hline \multicolumn{7}{|l|}{ Hospitalization time (days) } & \multirow[t]{2}{*}{$p$} \\
\hline & $\mathrm{n}^{*}$ & Mean & Standard deviation & Minimum & Median & Maximum & \\
\hline \multicolumn{8}{|l|}{ Congenital anomaly } \\
\hline Central nervous system & 71 & 24.9 & 31.9 & 1.0 & 14.0 & 201.0 & \\
\hline Heart and great vessels & 31 & 28.3 & 35.5 & 1.0 & 12.0 & 130.0 & \multirow[t]{6}{*}{$<0.01^{\S}$} \\
\hline Gastrointestinal/ abdominal wall & 35 & 34.5 & 36.2 & 1.0 & 26.0 & 160.0 & \\
\hline Urinary tract & 55 & 12.8 & 27.2 & 1.0 & 3.0 & 150.0 & \\
\hline Isolated hydrops & 8 & 9.9 & 12.6 & 1.0 & 5.0 & 36.0 & \\
\hline Musculoskeletal & 16 & 20.9 & 42.4 & 1.0 & 4.0 & 152.0 & \\
\hline Others & 32 & 24.8 & 51.1 & 1.0 & 9.0 & 274.0 & \\
\hline \multicolumn{8}{|l|}{ Early neonatal death } \\
\hline No & 176 & 28.0 & 37.5 & 1.0 & 14.0 & 274.0 & \multirow[t]{2}{*}{$<0.01^{f}$} \\
\hline Yes & 72 & 11.6 & 27.9 & 1.0 & 1.0 & 160.0 & \\
\hline \multicolumn{8}{|l|}{ Need for surgical treatment } \\
\hline No & 128 & 10.1 & 26.5 & 1.0 & 4.0 & 274.0 & \multirow[t]{2}{*}{$<0.01^{f}$} \\
\hline Yes & 120 & 37.3 & 38.9 & 1.0 & 24.0 & 201.0 & \\
\hline \multicolumn{8}{|l|}{ Neonatal infection } \\
\hline No & 184 & 14.3 & 23.7 & 1.0 & 6.0 & 150.0 & \multirow[t]{2}{*}{$<0.01^{f}$} \\
\hline Yes & 64 & 49.0 & 49.7 & 1.0 & 33.5 & 274.0 & \\
\hline \multicolumn{8}{|l|}{ Apgar score at the 5 th minute } \\
\hline$<7$ & 50 & 19.4 & 47.6 & 1.0 & 1.0 & 274.0 & \multirow[t]{2}{*}{$<0.01^{f}$} \\
\hline$\geq 7$ & 198 & 24.2 & 32.1 & 1.0 & 12.0 & 201.0 & \\
\hline
\end{tabular}

*Number of live newborns;

${ }^{\S}$ Kruskal-Wallis test;

${ }^{\int}$ Mann-Whitney test. 
scan; on the other hand, renal agenesis and lower urinary tract obstruction can be identified early, while milder obstructions are diagnosed later. ${ }^{26}$

In the present study, the prevalence of congenital heart disease was of $11.6 \%$, which is in agreement with the findings of studies conducted in tertiary reference centers. However, the analysis of this CA group showed the lowest concordance (28.1\%) between ultrasound scans level I and III. This can be explained by the difficulty of non-specialist sonographers in achieving a proper examination of the fetal heart and great vessels. It is well known that the detection rates of HGV defects increase with the examiner's ultrasound experience and training, and with the adoption of a systematic ultrasound examination of the fetal heart. 27,28

The prevalence of GI malformations was coincident with the data presented in other studies (13.8\%). ${ }^{29}$ Furthermore, GI anomaly was the CA group with the highest concordance ( $84 \%$ ) between findings of ultrasound scans level I and III. The most common GI malformations were abdominal wall defects, which can be easily identified by ultrasound scan performed after 13 weeks of gestation. In addition, esophageal atresia and small bowel obstructions are readily identified in the third trimester due to the presence of polyhydramnios.

Because of the multifactorial etiology of CAs, we proposed to assess the effect of maternal demographic factors on their occurrence; however few factors showed to have a positive correlation with CAs. This result is probably due to the small sample size. Moreover, the appropriate process of gathering and measuring information on targeted variables, such as skin color, smoking, use of medications and folic acid supplementation is not very reliable because of two main reasons: the occurrence of a mixed population in our country, and the low socioeconomic status of our patients.

According to our data, parity was a maternal risk factor for HGV defects. Multigravida have a higher risk of having children affected by this type of CA compared with primigravida or secundigravida. This finding is similar to the Csermely et $\mathrm{a}^{30}$ study that assessed 21,494 fetuses with different isolated malformations, and compared them to 34,311 normal controls. The authors showed that multiparity was a significant risk factor for the following five types of HGV anomalies: ventricular septal defect; ostium secundum atrial septal defect; persistence of arteriosus ductus; conotruncal cardiac defect; and ventricular outflow tract obstructions.

Smoking was a risk factor for ME anomalies. Overall, the prevalence of CAs does not seem to be increased among children of women who smoked during pregnancy. However, Morales-Suárez-Varela et $\mathrm{al}^{31}$ demonstrated that pregnant women who did not smoke but used nicotine patches had the risk of having children with ME anomalies (95\%CI: 1.53-4.52) increased by 2.6 times. The authors suggested that nicotine can interfere with the mechanism of genomic "imprinting" and lead to this type of CA. Another finding of the present study was the history of previous miscarriage as a risk factor for hydrops. It is well known that a large proportion of miscarriages is caused by genetic abnormalities, and their recurrence could be one of the causes of hydrops in the current pregnancy. ${ }^{32}$
There were two variables that provided protection against CAs. Maternal age $>19$ years and folic acid supplementation were associated with a decreased risk of GI malformations. Eckmann-Scholz et al $^{33}$ found that teenagers have an increased risk of having newborns with GI malformations, especially gastroschisis. This can be explained by the fact that pregnancy during adolescence may be associated with several risk conditions for CAs, such as use of illicit drugs, alcoholism, and nutritional deficiencies. ${ }^{33}$ Many studies point out to the effective prevention of fetal CAs with the regular folic acid supplementation mainly open neural tube defects. ${ }^{12,34}$

Changes of amniotic volume fluid were more frequent in fetuses with skeletal dysplasia and isolated hydrops. In skeletal malformations, a small thorax causes increased intrathoracic pressure and decreased fetal swallowing. ${ }^{32}$ In hydropic fetuses, polyhydramnios may be a consequence of increased urine production. ${ }^{32}$ In contrast, oligohydramnios was more common in the UT group, in which urine production is impaired by the existence of dysplastic kidneys or distal obstructions of the UT. ${ }^{26}$

In the present study, fetal death rates were high for all types of CAs compared with the general population due to the severity of malformations. ${ }^{35}$ In addition, preterm delivery rates were very high mainly for the GI anomalies and hydrops groups because of spontaneous labor caused by polyhydramnios or suspicion of ischemic bowel and compromised fetal wellbeing respectively. As a consequence, the elective cesarean section rates were also increased for those reasons, and also to obtain a successful perinatal management of neonates through delivery planning with a multi-professional team.

Neonatal adverse outcomes were extremely common in all CA groups. Hospitalization time was increased for all of them as a result of preterm delivery, low birth weight, Apgar score $<7$ at the 5th minute, neonatal infection, and need for surgical treatment. Neonatal death rates were significantly increased in all CA groups as a consequence of all perinatal complications previously described. The causes behind the low Apgar scores may be listed as difficult fetal extraction at the cesarean section or labor dystocia in skeletal dysplasia and hydrops; respiratory distress due to pulmonary hypoplasia, particularly in UT anomalies linked to oligohydramnios; and the presence of a small thorax or a large pleural fluid collection possible in ME CAs and hydrops respectively. Neonatal infections were more common among fetuses with HGS or GI anomalies because they usually require surgical treatments, blood vessel catheterization for parenteral nutrition, blood transfusions, and medications or fluid administration.

In summary, it was possible to identify several maternal risk factors for CAs. High rates of adverse perinatal outcomes were presented in all CA groups, and may differ according to the type of CA considered.

\section{References}

1 Liu X, Roth J. Development and validation of an infant morbidity index using latent variable models. Stat Med 2008;27(7):971-989

2 Mattison DR. Environmental exposures and development. Curr Opin Pediatr 2010;22(2):208-218 
3 Brent RL. Environmental causes of human congenital malformations: the pediatrician's role in dealing with these complex clinical problems caused by a multiplicity of environmental and genetic factors. Pediatrics 2004;113(4, Suppl)957-968

4 Jentink J, Dolk H, Loane MA, et al; EUROCAT Antiepileptic Study Working Group. Intrauterine exposure to carbamazepine and specific congenital malformations: systematic review and casecontrol study. BMJ 2010;341:c6581

5 Little J, Cardy A, Arslan MT, Gilmour M, Mossey PA. Smoking and orofacial clefts: a United Kingdom-based case-control study. Cleft Palate Craniofac J 2004;41(4):381-386

6 Boix H, Ortega-Aznar A, Vazquez E, Salcedo S, Roig-Quilis M. Brainstem dysgenesis in an infant prenatally exposed to cocaine. Pediatr Neurol 2010;42(4):295-297

7 Wattendorf DJ, Muenke M. Fetal alcohol spectrum disorders. Am Fam Physician 2005;72(2):279-282, 285

8 Zhao Z, Reece EA. Experimental mechanisms of diabetic embryopathy and strategies for developing therapeutic interventions. J Soc Gynecol Investig 2005;12(8):549-557

9 Gilbert-Barness E. Teratogenic causes of malformations. Ann Clin Lab Sci 2010;40(2):99-114

10 Marecki MA, Bozzette M. Infections in the perinatal period. J Perinat Neonatal Nurs 2008;22(3):173-174

11 Oster ME, Riehle-Colarusso T, Correa A. An update on cardiovascular malformations in congenital rubella syndrome. Birth Defects Res A Clin Mol Teratol 2010;88(1):1-8

12 Dolk H, Loane M, Garne E. The prevalence of congenital anomalies in Europe. Adv Exp Med Biol 2010;686:349-364

13 Arroll N, Sadler L, Stone P, Masson V, Farquhar C. Can we improve the prevention and detection of congenital abnormalities? An audit of early pregnancy care in New Zealand. N Z Med J 2013; 126(1380):46-56

14 Ruano R, Ali RA, Patel P, Cass D, Olutoye O, Belfort MA. Fetal endoscopic tracheal occlusion for congenital diaphragmatic hernia: indications, outcomes, and future directions. Obstet Gynecol Surv 2014;69(3):147-158

15 Gajewska-Knapik K, Impey L. Congenital lung lesions: Prenatal diagnosis and intervention. Semin Pediatr Surg 2015;24(4):156-159

16 Sanapo L, Moon-Grady AJ, Donofrio MT. Perinatal and delivery management of infants with congenital heart disease. Clin Perinatol 2016;43(1):55-71

17 Al-Matary A, Ali J. Controversies and considerations regarding the termination of pregnancy for foetal anomalies in Islam. BMC Med Ethics 2014;15:10

18 Grandjean H, Larroque D, Levi S. The performance of routine ultrasonographic screening of pregnancies in the Eurofetus Study. Am J Obstet Gynecol 1999;181(2):446-454

19 Stoll C, Tenconi R, Clementi M. Detection of congenital anomalies by fetal ultrasonographic examination across Europe. Community Genet 2001;4(4):225-232

20 European Surveillance of Congenital Anomalies (EUROCAT) [Internet]. Prenatal screening and diagnosis: prenatal detection rates. 2016 [cited 2016 May 23]. Available from: http://www.eurocat- network.eu/prenatalscreeninganddiagnosis/prenataldetection(pd) rates

21 Hadlock FP, Harrist RB, Martinez-Poyer J. In utero analysis of fetal growth: a sonographic weight standard. Radiology 1991;181(1): 129-133

22 Magann EF, Sanderson M, Martin JN, Chauhan S. The amniotic fluid index, single deepest pocket, and two-diameter pocket in normal human pregnancy. Am J Obstet Gynecol 2000;182(6): 1581-1588

23 Hosmer DW, Lemeshow S. Applied logistic regression. 2nd ed. New York: John Willey \& Sons; 2000

24 Population Screening Programmes. NHS Fetal Anomaly Screening Programme (FASP) [Internet]. 2016 [cited 2016 May 23]. Available from: https://www.gov.uk/topic/population-screening-programmes/fetal-anomaly

25 Sairam S, Al-Habib A, Sasson S, Thilaganathan B. Natural history of fetal hydronephrosis diagnosed on mid-trimester ultrasound. Ultrasound Obstet Gynecol 2001;17(3):191-196

26 Dias T, Sairam S, Kumarasiri S. Ultrasound diagnosis of fetal renal abnormalities. Best Pract Res Clin Obstet Gynaecol 2014;28(3): 403-415

27 Tegnander E, Eik-Nes SH. The examiner's ultrasound experience has a significant impact on the detection rate of congenital heart defects at the second-trimester fetal examination. Ultrasound Obstet Gynecol 2006;28(1):8-14

28 Pinto NM, Nelson R, Puchalski M, Metz TD, Smith KJ. Cost-effectiveness of prenatal screening strategies for congenital heart disease. Ultrasound Obstet Gynecol 2014;44(1):50-57

29 Barisic I, Clementi M, Häusler M, Gjergja R, Kern J, Stoll C; Euroscan Study Group. Evaluation of prenatal ultrasound diagnosis of fetal abdominal wall defects by 19 European registries. Ultrasound Obstet Gynecol 2001;18(4):309-316

30 Csermely G, Susánszky É, Czeizel AE, Veszprémi B. Possible association of first and high birth order of pregnant women with the risk of isolated congenital abnormalities in Hungary a population-based case-matched control study. Eur J Obstet Gynecol Reprod Biol 2014;179:181-186

31 Morales-Suárez-Varela MM, Bille C, Christensen K, Olsen J. Smoking habits, nicotine use, and congenital malformations. Obstet Gynecol 2006;107(1):51-57

32 Bellini C, Hennekam RC. Non-immune hydrops fetalis: a short review of etiology and pathophysiology. Am J Med Genet A 2012; 158A(3):597-605

33 Eckmann-Scholz C, von Kaisenberg CS, Alkatout I, Jonat W, RajabiWieckhorst A. Pathologic ultrasound findings and risk for congenital anomalies in teenage pregnancies. J Matern Fetal Neonatal Med 2012;25(10):1950-1952

34 Youngblood ME, Williamson R, Bell KN, Johnson Q Kancherla V, Oakley GP Jr. 2012 Update on global prevention of folic acidpreventable spina bifida and anencephaly. Birth Defects Res A Clin Mol Teratol 2013;97(10):658-663

35 Goldenberg RL, Kirby R, Culhane JF. Stillbirth: a review. J Matern Fetal Neonatal Med 2004;16(2):79-94 